\title{
Multiple natural enemies do not improve two spotted spider mite and flower western thrips control in strawberry tunnels
}

\author{
Gemma Albendín ${ }^{1 *}$, María Del Castillo García ${ }^{2}$, and José María Molina²
}

\begin{abstract}
Biological control techniques are commonly used in many horticultural crops in Spain, however the application of these techniques to Spanish strawberries are relatively recent. In this study the effectiveness of augmentative biological control techniques to control the two main strawberry (Fragaria $\times$ ananassa Duchesne) pest: the two-spotted spider mite (TSSM), Tetranychus urticae Koch (Acari: Tetranychidae), and the western flower thrips (WFT), Frankliniella occidentalis (Pergande) (Thysanoptera: Thripidae), through releases of the predatory mites Phytoseiulus persimilis Athias-Henriot, Neoseiulus californicus (McGregor), Amblyseius swirskii Athias-Henriot (Acari: Phytoseiidae), and Orius laevigatus (Fieber) (Heteroptera: Anthocoridae) were tested. Two-year results on the performance of treatments using combinations of these biocontrol agents are presented. In both years, all treatments resulted in the reduction of TSSM numbers; but no treatment was better than the release of $P$. persimilis alone $(\mathrm{P}<0.05)$. TSSM suppression varied among crop phases being greater early in the season. None of the treatments reduced significantly WFT numbers $(\mathrm{P}<0.05)$, and the established economic injury level (EIL) was surpassed from March to late April in both years. However, EIL was surpassed less times when treatment included $O$. laevigatus (2009: 20.7\%; 2010: $22.7 \%$ of samples). No effect of A. swirskii was observed when this mite was released. Results corroborate that biological control techniques for TSSM and WFT are feasible for high-plastic tunnel strawberries. Under the conditions in our study no additive effects were observed, and there was not advantage in the release of multiple natural enemies.
\end{abstract}

Key words: Biological control, combined releases, Fragariaxananassa, Frankliniella occidentalis, Orius laevigatus, Phytoseiids, Tetranychus urticae.

\section{INTRODUCTION}

The strawberry (Fragaria xananassa Duchesne, Rosaceae) is one of the most consumed berry fruit worldwide having experienced one of the highest growth rates of consumption of all fruit and vegetables over the two last decades. The USA is the world's largest producer of strawberries, producing over 1.4 million tons in 2012, and accounting for the $33.3 \%$ of the total world's strawberry production. Spain was the fourth larger producer, with the $7.1 \%$ of the total production; being surpassed by Mexico (8.8\%), and Turkey (8.6\%) (FAOSTAT, 2012).

Strawberries, mostly for the fresh market, are grown in other Spanish regions but production from the province of Huelva (Andalusia, South-Western Spain) dominates. More than $95 \%$ of this crop is located in this

\footnotetext{
${ }^{1}$ Universidad de Cádiz, Laboratorio de Toxicología, Polígono Río San Pedro s/n Puerto Real, 11510 Cádiz, España.

*Corresponding author (gemma.albendin@uca.es).

${ }^{2}$ Junta de Andalucía, Consejería de Agricultura, Pesca y Desarrollo Rural, Instituto de Formación e Investigación Agraria y Pesquera (IFAPA), Centro Las Torres-Tomejil, Ctra. Sevilla-Cazalla, km 12,2. 41200 Alcalá del Río, Sevilla, España.

Received: 29 July 2014.
}

Accepted: 4 December 2014.

doi:10.4067/S0718-58392015000100009 province. Climatic and soil characteristics make this area exceptional for strawberry production, allowing to supply the international markets early in the season (LópezAranda, 2008).

Strawberries in Huelva are usually grown on the same place year after year under unheated roll-up sided high plastic tunnels (Spanish tunnels); this semi-open cultivation system benefits growers by improving earliness (Hancock and Simpson, 1995; MacNaeidhe, 1999; López-Aranda, 2008). Planting system employs fresh short-day strawberry cultivars plants from highelevation nurseries; usual plantation dates encompasses the second half of October, and harvest dates extend from the end of December to the first half of June. There is a registered surface of strawberry cultivation of 6600 ha in Huelva, with a production around 250000 t (LópezAranda, 2008; Junta de Andalucía, 2011).

There are many arthropod pests that affect strawberries; but the two-spotted spider mite (TSSM), Tetranychus urticae Koch (Acari: Tetranychiidae), and the western flower thrips (WFT), Frankliniellaoccidentalis (Pergande) (Thysanoptera: Thripidae), are key pests of strawberries (Coll et al., 2007; Strand, 2008; Alvarado, 2009; Zalom et al., 2014). Strawberry plants are often simultaneously infested by both species, which can cause reductions both in yield and fruit quality when their population densities 
are high. TSSM feeding injuries produce a reduction of photosynthesis and transpiration, followed by reduction of total yield per plant, individual fruit size and number of fruits per plant. Damage to strawberry caused by WFT is characterized by brown and withered stigma and anthers, slight necrotic spots on the calyx of the flower, and reduction in flower receptacle size at high thrips density. WFT feeding causes net-like russeting in the surface of fruits, reducing shelf-life, and fruit appearance (Coll et al., 2007; Zalom et al., 2014). The small size, ethological traits, high reproductive potential, and ability to build up resistance to chemicals of both pests make difficult to manage them only with pesticides (Van Leeuwen et al. 2010; Zalom et al., 2014).

Pesticide residues have become a major worldwide issue resulting in legislative actions to limit and regulate their use. In Europe the Directive 2009/128/ EC has regulated the availability and use of many active ingredients. The restricted numbers of chemicals approved for Integrated Pest Management (IPM) use in Andalusian strawberries (Junta de Andalucía, 2014), and the market pressures to reduce pesticide residues make non-chemical methods desirable for the control of strawberry pests (Strand, 2008; Alvarado, 2009). Today more than $60 \%$ of total strawberry production in Andalusia uses biological control as part of IPM strategies. Biological control techniques can reduce pesticide applications, making the crop environment safer to work in, and reducing pesticide residues (Bale et al., 2008). Augmentative techniques through releases of predatory mites and insects are usually used in horticulture, methods are well established, and some biocontrol agents and protocols are already in use for strawberries (Collier and Van Steenwyk, 2004; Rhodes and Liburd, 2006; López-Aranda, 2008; Pottorff and Panter, 2008). However, performance of biocontrol agents may differ between regions, cropping systems or crops (Collier and Van Steenwyk, 2004; Fitzgerald et al., 2007; Pottorff and Panter, 2008). Therefore, before recommending any strategy, it is necessary their evaluation in the field.

Spider mites and thrips are currently being controlled with the release of both specialist and generalist predators. Phytoseiidae is the most important family of acarine predators used in pest management programs (Gerson and Weintraub, 2007; Hoy, 2011). Phytoseiulus persimilis
Athias-Henriot and Neoseiulus californicus (MacGregor) are among the species most used in horticultural and greenhouse crops, having been employed in strawberries for TSSM control (Fraulo and Liburd, 2007; Palevsky et al., 2008). Amblyseius swirskii (Athias-Henriot) is a Mediterranean phytoseiid species considered as a primary predator of thrips and whiteflies; it has been recommended and used to control TSSM as well as other pests in greenhouse and strawberry crops (Elsawi and Alazzazy, 2007; Gerson and Weintraub, 2007; Alvarado, 2009; Xu and Enkegaard, 2010; Sáenz-de Cabezón et al., 2010; Calvo et al., 2011; Kutuk et al., 2011). Species of the genus Orius (Heteroptera: Anthocoridae) are commonly found on cultivated and wild plants in the Mediterranean Europe, and have received much attention as biocontrol agents for thrips (Tommasini et al., 2004). Among them, Orius laevigatus (Fieber), the minute pirate bug, is a generalist predator commonly used to control thrips in greenhouses (Weintraub et al., 2011).

The main goals of this research were to determine if within a strategy of zero-residues for high-plastic tunnel grown strawberries the control of TSSM and WFT can be achieved by using the proposed species: Phytoseiulus per similis, Neoseiulus californicus, Amblyseius swirskii, and Orius laevigatus, and evaluate the relative effectiveness of the combined use of multiple predatory species in this environment.

\section{MATERIAL AND METHODS}

\section{Study site and experimental design}

Field trials were carried-out during two consecutive growing seasons using commercially available biocontrol agents intended to control TSSM and WFT at 'El Cebollar' Experimental Station ( $37^{\circ} 14^{\prime} 29^{\prime \prime}$ N, $06^{\circ} 48^{\prime} 03$ ” W), $10 \mathrm{~km}$ NE of Huelva, Spain. Strawberry plants were cultivated according to local conventional grower practices, and recommendations established in the Spanish and Andalusian regulation for IPM strawberries (BOJA, 2008; Table 1). Short-day length strawberry 'Camarosa' (Bringhurst et al., 1994) was planted in the third week of October each year (winter plantation) in raised beds covered with black plastic mulch, and drip irrigation. Strawberry season extended until the last week of May in both years.

Table 1. Andalusian regulation for thrips and two-spotted spider (TSSM) mite in strawberry.

\begin{tabular}{|c|c|c|}
\hline & Frankliniella occidentalis (Pergande) & Tetranychus urticae Koch $^{1}$ \\
\hline Sampling & $\begin{array}{l}\text { Examination } 1 \text { flower per plant, recording individual numbers } \\
\text { of larvae and/or adults }\end{array}$ & $\begin{array}{l}\text { Examination } 2 \text { leaves per plant, one young leaf and one } \\
\text { older, recording adult females }\end{array}$ \\
\hline Evaluation scale & $\begin{array}{l}0=\text { flower with }<3 \text { mobile forms } \\
1=\text { flower with } \geq 3 \text { mobile forms }\end{array}$ & $\begin{array}{l}0=\text { No adult females } \\
1=\geq 1 \text { adult females } \\
15 \% \text { leaves occupied until the end of February }\end{array}$ \\
\hline Economic injury levels (EIL) & $70 \%$ of flowers with 3 or more mobile forms & $\begin{array}{l}25 \% \text { leaves occupied in the rest of season if the leaves } \\
\text { occupied by Phytoseiid are }<50 \% \text { of leaves occupied by } \\
\text { TSSM }\end{array}$ \\
\hline
\end{tabular}

${ }^{1}$ We have considered a leaf occupied when TSSM mobile forms were present. 
Experimental design was a Latin square with four replicates by treatment in both years. Elementary plots had an area of $36 \mathrm{~m}^{2}(12 \mathrm{~m} \times 3 \mathrm{~m})$, with 240 strawberry plants disposed in two rows on two raised beds. Two adjacent high tunnels (each $6.6 \mathrm{~m}$ wide $\times 60 \mathrm{~m}$ long) were used in the trials. Within each tunnel, plots were separated by an unplanted area of $3 \mathrm{~m}$, and one raised bed of plants (buffer row). After transplanting, tunnels were covered with polyethylene plastic to keep the tunnel hot during the winter. Plants received no chemicals treatments during the trials. To minimize pesticide drifts from nearby plots in the farm, a vertical separation with polyethylene plastic supported by a metal frame was placed as a barrier on either side of the trial.

Phytoseiid species and $O$. laevigatus were supplied by Koppert España SL (Almería, Spain). Phytoseiulus persimilis was released from $100 \mathrm{~mL}$ bottles containing 2000 adults in sawdust. Neoseiulus californicus was supplied in $500 \mathrm{~mL}$ bottles containing 5000 mites in inert pellets. In 2009 Amblyseius swirskii was released as nymphs and adults from $500 \mathrm{~mL}$ bottles (50 000 mites); paper sachets with 250 mites plus storage mites mixed with bran were used in 2010. Orius laevigatus was supplied in $100 \mathrm{~mL}$ bottles containing a mix of 2000 adults and $5^{\text {th }}$ instar nymphs in buckwheat husks and vermiculite. All species were released as preventive treatments on the same day after their arrival to the farm following the guidelines established by the supplier. Species, combinations, doses and dates of releases are summarized up in Table 2.

\section{Sampling and data analysis}

Plots were sampled weekly, beginning approximately 1-mo after strawberries were planted and once new leaves were present. TSSM numbers were assessed by sampling two leaves (one young and another older) randomly selected taken from each of five randomly selected plants per plot (40 leaves per treatment), and recording all motiles present. WFT numbers were monitored by examining five randomly selected flowers per plot (20 per treatment), and recording all larvae and adults present. Each leaf or flower was checked in the field with the aid of $20 \mathrm{X}$ hand lens (Lenscope, Bausch \& Lomb, Berlin, Germany).

Differences between TSSM and WFT numbers were separately analyzed in both years using Latin square ANOVA. If a significant ANOVA was detected, means were compared using one-tailed Dunnett's multiple comparisons test with a control (Quinn and Keough, 2006). Phytoseiulus persimilis alone was used as control treatment for TSSM analyses, and the treatment that included $O$. laevigatus was employed as control treatment for WFT analyses, because these are the species most commonly available and most commonly released in horticulture and biologically grown strawberries to control these pests (Heon and Park, 2006; Alvarado, 2009; Weintraub et al., 2011).

The economic injury levels (EILs) established in the Andalusian regulation for IPM strawberry production are based on percentage of occupation of leaves (TSSM), or flowers (WFT), and crop phase (Table 1; BOJA, 2008). Thus, within each strawberry season TSSM data were separated in three periods based on treatment dates and time during the season. Periods included: pre-treatment (3 wk prior to first treatment), early crop (post-treatment to end of February), and late crop (from 1 March to the last strawberry harvest of each year). WFT data were separated only into two periods based on treatment application dates of $O$. laevigatus and A. swirskii.

Performance and trend throughout the strawberry season were compared for each treatment and season using the percentages of occupation of leaves (TSSM) and flowers (WFT) by means of Kruskal-Wallis oneway nonparametric ANOVA followed by all-pairwise comparisons tests for mean separation ( $\mathrm{Z}$ test, $\alpha=0.05$ ).

Raw TSSM and WFT data were transformed before analyses using logarithmic transformation $\left(\mathrm{x}^{\prime}=\log (\mathrm{x}+1)\right.$ ) to meet the assumption of homogeneity of variance, and square root transformation $\left(x^{\prime}=\sqrt{ } x+1\right)$ was applied to percentages. All statistical analyses were performed using Statistix 9.0 for Windows (Analytical Software, Tallahassee, Florida, USA).

Table 2. Biocontrol agents and combination treatments employed in the trial.

\begin{tabular}{|c|c|c|c|c|c|c|}
\hline \multirow[b]{2}{*}{ Biocontrol agent } & \multicolumn{3}{|c|}{2009} & \multicolumn{3}{|c|}{2010} \\
\hline & Release date & Dose (ind. $\mathrm{m}^{-2}$ ) & Treatments & Release date & Dose (ind. $\mathrm{m}^{-2}$ ) & Treatments \\
\hline Phytoseiulus persimilis (Pper) & $\begin{array}{c}17 \text { December } 2008 \\
\text { (week 51) }\end{array}$ & 10 & $\begin{array}{c}\text { Pper } \\
\text { Pper/Ncal } \\
\text { Pper/Aswi } \\
\text { Pper/Ncal/Olae }\end{array}$ & $\begin{array}{l}21 \text { December } 2009 \\
\text { (week 52) }\end{array}$ & 10 & $\begin{array}{c}\text { Pper } \\
\text { Pper/Ncal } \\
\text { Pper/Ncal/Olae }\end{array}$ \\
\hline \multirow[t]{2}{*}{ Neoseiulus californicus (Ncal) } & $\begin{array}{c}17 \text { December } 2008 \\
\text { (week 51) }\end{array}$ & 15 & $\begin{array}{c}\text { Pper/Ncal } \\
\text { Pper/Ncal/Olae }\end{array}$ & $\begin{array}{l}21 \text { December } 2009 \\
\text { (week 52) }\end{array}$ & 15 & $\begin{array}{c}\text { Pper/Ncal } \\
\text { Ncal/Aswi } \\
\text { Pper/Ncal/Olae }\end{array}$ \\
\hline & $\begin{array}{c}5 \text { February } 2009 \\
(\text { week 6) }\end{array}$ & 15 & $\begin{array}{c}\text { Pper/Ncal } \\
\text { Pper/Ncal/Olae }\end{array}$ & $\begin{array}{c}\text { 26 January } 2010 \\
\text { (week 4) } \\
\text { 16 February } 2010 \\
\text { (week 7) }\end{array}$ & $\begin{array}{l}15 \\
25\end{array}$ & $\begin{array}{c}\text { Pper/Ncal } \\
\text { Pper/Ncal/Olae } \\
\text { Ncal/Aswi }\end{array}$ \\
\hline Orius laevigatus (Olae) & $\begin{array}{c}11 \text { February } 2009 \\
\text { (week 7) }\end{array}$ & 3.5 & Pper/Ncal/Olae & $\begin{array}{c}23 \text { February } 2010 \\
(\text { week } 8)\end{array}$ & 3.5 & Pper/Ncal/Olae \\
\hline Amblyseius swirskii (Aswi) & $\begin{array}{l}11 \text { February } 2009 \\
\text { (week 7) }\end{array}$ & 70 & Pper/Aswi & $\begin{array}{l}23 \text { February } 2010 \\
\text { (week } 8)\end{array}$ & 50 & Ncal/Aswi \\
\hline
\end{tabular}




\section{RESULTS}

\section{8-2009 strawberry season}

Natural population of TSSM was found in the trial. Mean TSSM density during the pre-treatment period was similar in all treatments $\left(F_{3,15}=0.66 ; p=0.605\right)$. A reduction in TSSM numbers was observed during the early phase of the crop in all treatments except the one in which P.persimilis, $N$. californicus, and $O$. laevigatus were released together; however, no significant differences were observed $\left(\mathrm{F}_{3,15}=\right.$ $1.97, \mathrm{p}=0.219$ ). TSSM population suppression continued later in the crop season again without differences among treatments $\left(F_{3,15}=0.92, p=0.942\right.$; Figure $\left.1 \mathrm{~A}\right)$.

Percentages of leaves with TSSM decreased from pretreatment to the end of the season in all treatments. No differences in the mean percentages of strawberry leaves with TSSM were found (Table 3). However, in the early crop phase, EIL was surpassed in four sampling dates for the treatment with $P$. persimilis $+N$. californicus; three dates in the combination $P$. persimilis $+N$. californicus $+O$. laevigatus; and two dates when $P$. persimilis was combined with $A$. swirskii. Late EIL was surpassed only in the treatment that combined P. persimilis $+A$. swirskii.

Mean WFT density was similar among treatments in 2009 before the releases $\left(\mathrm{F}_{3,15}=1.02 ; \mathrm{p}=0.447\right)$. WFT population increased more than 20 times after releases $(0.21 \pm 0.03$ to $4.86 \pm 0.18$ thrips per flower). This increase was observed in all treatments. There were no significant differences in WFT numbers among treatments $\left(\mathrm{F}_{3,15}=\right.$
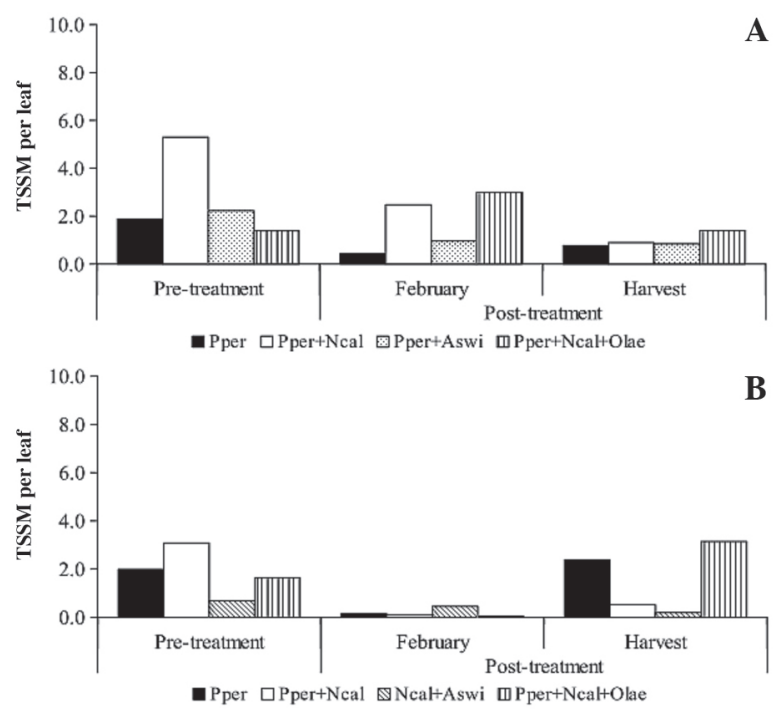

Means with same letter are not significantly lower than the control treatment: Pper (one-tailed Dunnett's multiple comparison test, $\alpha=0.05$ ). Pper: Phytoseiulus persimilis alone; Pper+Ncal: P. persimilis + Neoseiulus californicus combination; Pper+Aswi: P. persimilis + Amblyseius swirskii combination; Ncal+Aswi: N. californicus $+A$ swirskii combination; Pper+Ncal+Olae: P. persimilis $+N$. californicus + Orius laevigatus combination.

Figure 1. Two-spotted spider mite (TSSM) numbers during the different crop phases in the two strawberry seasons of study: 2009 (A) and $2010(B)$. Data presented as means $( \pm \mathrm{SE})$.
Table 3. Average percentages of leaves with two-spotted spider mite motiles in post-release phases during the two strawberry seasons considered in this study.

\begin{tabular}{lccccc}
\hline & \multicolumn{2}{c}{2009} & & \multicolumn{2}{c}{2010} \\
\cline { 2 - 3 } \cline { 5 - 6 } Treatments & Early & Late & & Early & Late \\
\hline Pper & $7.78 \pm 1.36 \mathrm{a}$ & $10.21 \pm 3.09 \mathrm{a}$ & & $1.43 \pm 1.01 \mathrm{a}$ & $16.04 \pm 3.01 \mathrm{a}$ \\
Pper+Ncal & $14.16 \pm 3.61 \mathrm{a}$ & $7.70 \pm 2.77 \mathrm{a}$ & & $2.15 \pm 0.92 \mathrm{a}$ & $6.04 \pm 2.55 \mathrm{a}$ \\
Pper+Aswi & $12.22 \pm 4.61 \mathrm{a}$ & $8.33 \pm 2.59 \mathrm{a}$ & - & - & - \\
Ncal+Aswi & - & - & & $7.50 \pm 5.16 \mathrm{a}$ & $6.25 \pm 1.38 \mathrm{a}$ \\
Pper+Ncal+Olae & $10.56 \pm 3.32 \mathrm{a}$ & $7.29 \pm 2.29 \mathrm{a}$ & & $1.43 \pm 0.00 \mathrm{a}$ & $11.46 \pm 4.77 \mathrm{a}$ \\
Kruskal-Wallis & $\mathrm{F}_{3,15}=0.46$ & $\mathrm{~F}_{3,15}=0.19$ & & $\mathrm{~F}_{3,15}=0.88$ & $\mathrm{~F}_{3,15}=2.41$ \\
ANOVA & $\mathrm{p}=0.718$ & $\mathrm{p}=0.899$ & $\mathrm{p}=0.481$ & $\mathrm{p}=0.117$ \\
\hline
\end{tabular}

Treatments with the same letter are not significantly different from each other. Errors bars represent standard error of the mean.

Pper: Phytoseiulus persimilis alone; Pper+Ncal: P. persimilis + Neoseiulus californicus combination; Pper+Aswi: P. persimilis + Amblyseius swirskii combination; Ncal+Aswi: N. californicus + A. swirskii combination; Pper+Ncal+Olae: $P$. persimilis $+N$. californicus + Orius laevigatus combination.

$1.92, \mathrm{p}=0.228$; Figure 2A). The percentage of flowers with three or more thrips was less than $70 \%$ (EIL) in all treatments before releases. No difference in the total percentage of flowers with three or more thrips was observed at the end of the season (Table 4). The EIL was surpassed in the trial after the releases of $O$. laevigatus and A. swirskii from the first week of March to the second week of April. EIL was surpassed in eight sampling dates when $P$. persimilis was combined with $N$. californicus; seven dates in the treatment that combined $P$. persimilis + A. swirskii; six dates in the P. persimilis treatment; and four dates in the treatment that included $O$.laevigatus.
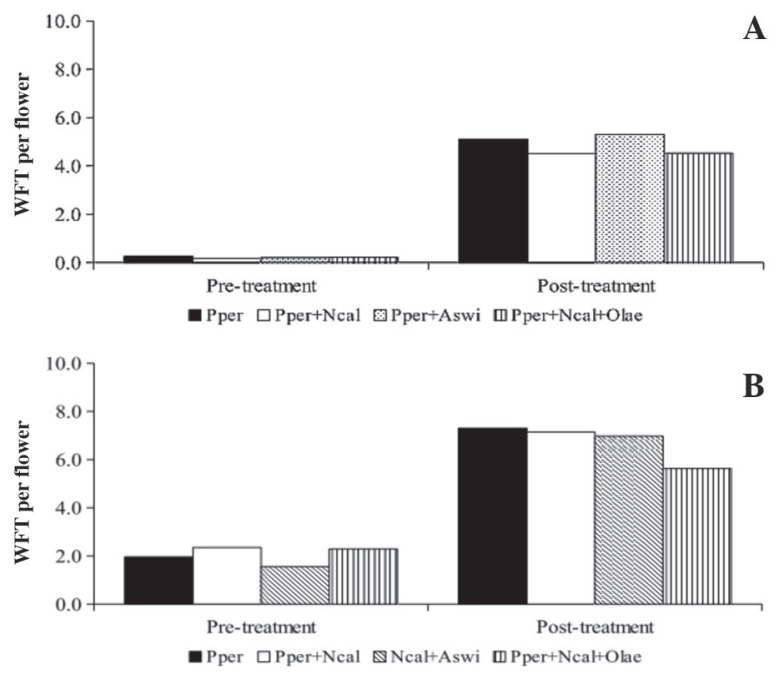

Pper: Phytoseiulus persimilis alone; Pper+Ncal: P. persimilis + Neoseiulus californicus combination; Pper+Aswi: P. persimilis + Amblyseius swirskii combination; Ncal+Aswi: N. californicus $+A$. swirskii combination; Pper+Ncal+Olae: P. persimilis $+N$. californicus + Orius laevigatus combination.

Means with same letter are not significantly lower than the control treatment: Pper+Ncal+Olae (one-tailed Dunnett's multiple comparison test, $\alpha=0.05)$.

Figure 2. Western flower thrips (WFT) numbers during the different crop phases in the two strawberry seasons of study: 2009 (A) and 2010 (B). Data presented as means $( \pm \mathrm{SE})$. 
Table 4. Average percentages of flowers that surpassed economic injury level for western flower thrips ( $\geq 3$ individuals per flower) during post-release phase of the two strawberry seasons.

\begin{tabular}{lcc}
\hline Treatments & 2009 & 2010 \\
\hline Pper & $59.34 \pm 1.39 \mathrm{a}$ & $78.46 \pm 2.59 \mathrm{a}$ \\
Pper+Ncal & $61.33 \pm 3.31 \mathrm{a}$ & $71.92 \pm 2.97 \mathrm{ab}$ \\
Pper+Aswi & $65.67 \pm 4.91 \mathrm{a}$ & - \\
Ncal+Aswi & - & $76.15 \pm 0.45 \mathrm{ab}$ \\
Pper+Ncal+Olae & $56.67 \pm 2.07 \mathrm{a}$ & $66.15 \pm 2.95 \mathrm{~b}$ \\
Kruskal-Wallis ANOVA & $\mathrm{F}_{3,15}=0.88$ & $\mathrm{~F}_{3,15}=5.24$ \\
& $\mathrm{p}=0.477$ & $\mathrm{p}=0.015$ \\
\hline
\end{tabular}

Treatments with the same letter are not significantly different from each other. Errors bars represent standard error of the mean.

Pper: Phytoseiulus persimilis alone; Pper+Ncal: P. persimilis + Neoseiulus californicus combination; Pper+Aswi: P. persimilis + Amblyseius swirskii combination; Ncal+Aswi: N. californicus + A. swirskii combination; Pper+Ncal+Olae: $P$. persimilis $+N$. californicus + Orius laevigatus combination.

No Phytoseiids were observed in the trial before releases were done. P. persimilis mites were observed in the early and late crop seasons. The higher population of this mite was observed in the $P$. persimilis treatment $(0.22 \pm 0.10$ mites per leaf $)$, followed by the treatment $P$. persimilis + A. swirskii $(0.12 \pm 0.03)$. Population was lower in the $P$. persimilis $+N$. californicus, and similar to the treatment $P$. persimilis $+N$. californicus $+O$. laevigatus. No differences in $P$. persimilis numbers were observed among treatments $\left(\mathrm{F}_{3,15}=1.48, \mathrm{P}=\right.$ $0.248)$. Phytoseiulus persimilis numbers decreased in all treatments except in the $P$. persimilis $+A$. swirskii treatment from the early to the late crop phase. Neoseiulus californicus mites were observed in both periods of the crop season; it reached a population of $0.05 \pm 0.02$ mites per leaf in the early crop phase, and $0.02 \pm 0.01$ motiles per leaf in the late crop season. Few numbers of this mite were recorded in treatments in which no releases were done. Neoseiulus californicus was most abundant in the $P$. persimilis $+N$. californicus treatment $(0.09 \pm 0.04$; $\left.\mathrm{F}_{3,15}=4.88, \mathrm{p}=0.010\right)$. Despite A. swirskii being released only in combination with $P$. persimilis, the species was observed throughout the entire post-release period in others treatments. Very few mites were observed until the end of February, and although numbers increased late in the season, the abundance of this species was low $(0.02$ \pm 0.01 mites per leaf). Orius laevigatus was observed in all treatments after release. Numbers were higher in the $P$. persimilis $+N$. californicus $+O$. laevigatus treatment $(0.35 \pm 0.03$ bugs per flower). There were significant differences in O. laevigatus numbers among treatments at the end of the season $\left(F_{3,15}=7.7, p=0.017\right)$.

\section{9-2010 strawberry season}

No difference in TSSM natural population density between both years was found $\left(\mathrm{F}_{1,31}=0.96, \mathrm{p}=0.335\right)$. TSSM numbers were also similar among treatments in the pre-treatment phase $\left(\mathrm{F}_{3,15}=0.48, \mathrm{p}=0.709\right)$. A reduction in TSSM numbers was observed in all treatments early in the season but without significant mean differences $\left(F_{3,15}=1.00 ; p=0.455\right)$. Late in the crop season TSSM numbers increased in the P.persimilis and P.persimilis +
$N$. californicus $+O$. laevigatus treatments; however, once again no differences were found between treatments $\left(\mathrm{F}_{3,15}\right.$ $=1.64 ; \mathrm{p}=0.276$; Figure 2A).

No difference in the mean percentage of leaves with TSSM motiles was observed. EIL was surpassed in the trial after the releases of biocontrol agents only in two sampling dates of the late crop phase in the treatment with P. persimilis (Table 3). WFT population in 2010 was $10 \mathrm{X}$ greater $(2.04 \pm 0.10$ WFT per flower) than in 2009 $(0.21 \pm 0.03 \mathrm{WFT}$ per flower) in the pre-treatment phase. WFT numbers were lower in plots when $N$. californicus + A. swirskii were released $\left(\mathrm{F}_{3,15}=16.17 ; \mathrm{p}=0.003\right)$. As in 2009, WFT population increased from March to the end of the strawberry season, this increase was lower in the treatment that included $O$. laevigatus; however, no significant differences were observed $\left(\mathrm{F}_{3,15}=1,92 ; \mathrm{p}=\right.$ 0.228 ; Figure 2B). Differences in mean percentage of flowers with three or more thrips were observed postrelease. The percentage of flowers that surpassed EIL was higher when $P$. persimilis was released alone and lower when $O$. laevigatus was included in the combination (Table 4).

As in the 2008-2009 season, no Phytoseiids were observed in the trial before releases were done. Phytoseiulus persimilis reached an average of $0.07 \pm$ 0.03 mites per leaf when released alone; P. persimilis numbers were lower in all the combination treatments, but there were not significant differences $\left(F_{3,15}=0.30\right.$, $p$ $=0.822)$. Neoseiulus californicus mites were observed in all treatments. This species reached an average of 0.06 \pm 0.02 motiles per leaf at the end of the season. Higher values were observed in the P.persimilis $+N$. californicus $+O$. laevigatus treatment $(0.10 \pm 0.05$ mites per leaf $)$. The numbers of $N$. californicus did not differ among treatments $\left(\mathrm{F}_{3,15}=1.31, \mathrm{p}=0.295\right)$.

Very few A. swirskii mites were recorded in the 20092010 field season. The highest numbers of this species reached $0.04 \pm 0.02$ mites per leaf. Amblyseius swirskii numbers were higher in plots where it was initially released $\left(F_{3,15}=4.70, P=0.011\right)$. Orius laevigatus were also found in all treatments. The higher numbers of $O$. laevigatus were found in the P. persimilis $+N$. californicus treatment $(0.31 \pm 0.04$ bugs per flower). There were no significant differences in $O$. laevigatus numbers among treatments at the end of the season $\left(F_{3,15}=0.5, p=0.693\right)$.

\section{DISCUSSION}

There are several studies that compare the effectiveness of combining multiple species releases to that of a single species in order to control single or multiple preys (Fitzgerald et al., 2007). Multiple natural enemy releases have been employed as a way to improve pest suppression also in strawberries (Rhodes et al., 2006; Cakmak et al., 2009; de Menten, 2011; Rahman et al., 2011). However, using multiple species may enhance or may reduce pest 
control, and there is no general agreement on whether the use of single or multiple biocontrol agents is economically profitable and beneficial for pest management (Gerson and Weintraub, 2007; Chow et al., 2010; Onzo et al., 2014). We found no significant differences when multiple predatory species were released to control TSSM numbers when compared with the release of P. persimilis alone. Schausberger and Walzer (2001) reported a similar situation with $P$. persimilis and $N$. californicus when released to control of Tetranychus cinnabarinus Boisduval on gerbera plants, and Cakmak et al. (2009) found that the control of this species on strawberries was not improved when these two species were released together. TSSM suppression varied among crop phases being proportionally greater in the early crop phase in both years. The levels of control of spider mite species attained by Phytoseiid predatory mites vary from species to species, and depend, among others factors, on predator/ prey ratios (Hoy, 2011). Prey preference also plays an important role in the performance of polyphagous predators (Rasmy et al., 2004; Greco et al., 2005). Thus, when multiple species are present, there are some potential for trophic interactions (Walzer et al., 2001); cannibalism, inter- and intra-guild predation have been well documented for Phytoseiid mites and Orius species when the preferred prey level is low (Buitenhuis et al., 2009; Hoy, 2011). WFT and TSSM infesting cucumber were efficiently controlled with Orius insidiosus (Say) and $P$. persimilis (Fejt and Jarosik, 2000), van Baal et al. (2007) reported thrips control using N. californicus intended for TSSM control. However, when $O$. insidiosus was feed using either $F$. occidentalis or $T$. urticae separately higher suppression of the pest population was observed than when the two pests were simultaneously offered (Xu et al., 2006; Xu and Enkegaard, 2010).

Lower WFT numbers were found when $O$. laevigatus was released, but there were no significant differences in the reduction of WFT numbers among treatments. Amblyseius swirskii is a well known biocontrol agent of thrips' species in greenhouse crops (Wimmer et al., 2008; Arthurs et al., 2009); but in this study the release of this species did not resulted in significant reduction of WFT numbers. Variability in efficacy of A. swirskii on different crops has been related to trichome density (Buitenhuis et al., 2014). Previously, Elsawi and Alazzazy (2007) reported that $A$. swirskii successfully developed and reproduced on strawberry leaves feeding on TSSM, but that cultivar's characteristics affected behavior and other important life traits of this species such as longevity and fecundity. Poor adaptation to strawberry 'Camarosa', because of 'moderate' foliar pubescence (Voth et al., 1994) might be one feasible cause for explaining the low establishment, and lack of success of A. swirskii in our trials. Also, it is know that some Orius species will be prone to attack to any Phytoseiid present in strawberry flowers (Cloutier and Johnson, 1993); thus we can expect some degree of inter-specific competition with $O$. laevigatus when released together. Inter-guild competition through prey selection and predation may have played an important role in WFT control by A. swirskii.

The decrease in the numbers of WFT observed in the treatment with $O$. laevigatus was not sufficient to maintain WFT numbers below the present-day EIL for Andalusian strawberries. However, the early releases of $O$. laevigatus controlled thrips efficiently when the recommended EIL for winter planted strawberries in other countries (10 WFT per flower; Coll et al., 2007; Zalom et al., 2014) is applied. A low EIL for WFT such as the present-day on Andalusian strawberries (3 WFT per flower; BOJA, 2008) can result in unnecessary chemical treatments, which in turn can affect the implementation of other biological control strategies (Shakya et al., 2010). However, field data on the performance of natural enemies on controlling strawberry pests are still scarce in our country, and there is a lack of information on their comparative effectiveness.

Finally, high-plastic tunnels are not tight-enclosed controlled cropping systems such as high-tech greenhouses. The meteorological conditions of each season may play a significant role in the establishment of natural enemies and subsequent performance of biological control techniques. Dispersal or emigration from or into the crop is one of the factors limiting the effectiveness of biological control (Collier and Van Steenwyk, 2004). In our trials, Phytoseiids and $O$. laevigatus were recorded from treatments in which they were not initially released. Such situation, usual in open-field studies, has been mainly attributed to low prey density or absence of preferred prey (Rhodes et al., 2006). We suggest that some techniques to improve the establishment and maintenance of natural enemy populations in strawberry fields must be tested. Among these techniques the use of weed strips or banker plants seem to be appropriate in an augmentation/ conservation strategy (Frank, 2010).

\section{CONCLUSIONS}

Our results support that control of two-spotted spider mite can be achieved in strawberries grown under highplastic tunnels using the proposed species. Our data also support that early releases of Orius laevigatus seem to be a promising way to improve western flowers thrips control. However, there was not advantage in the release of multiple natural enemies, in the conditions of the present study. Therefore, further studies need to be carried out to determine the suitability of these and others species, combinatory techniques, and the release rates of each species that can effectively suppress pest population.

\section{ACKNOWLEDGEMENTS}

We thank César Rodríguez-Saona for useful comments and corrections of a first draft of this manuscript. We 
thank to V. Ramos (IFAPA Las Torres-Tomejil), and the staff at the 'El Cebollar' Experimental Station (IFAPA Las Torres-Tomejil) for their assistance in managing the research plots. Funding for this work was provided by IFAPA and Koppert España SL through research project $\mathrm{N}^{\circ}$ CC7408.

\section{LITERATURE CITED}

Alvarado, P. 2009. El control integrado en los fresales de Huelva basado en el control biológico. p. 231-248. In $11^{\circ}$ Symposium Nacional de Sanidad Vegetal: Uso sostenible de fitosanitarios, Sevilla. 27-29 enero. Junta de Andalucía, Consejería de Agricultura y Pesca, Sevilla, España.

Arthurs, S., C.L. McKenzie, J. Chen, M. Dogramaci, M. Brennan, K. Houban, et al. 2009. Evaluation of Neoseiulus cucumeris and Amblyseius swirskii (Acari: Phytoseiidae) as biological control agents of chilli thrips, Scirtothrips dorsalis (Thysanoptera: Thripidae) on pepper. Biological Control 49:91-96.

Bale, J.S., J.C. van Lenteren, and F. Bigler. 2008. Biological control and sustainable food production. Philosophical Transactions of the Royal Society B 363(1492):761-776.

BOJA. 2008. Orden de 5 de diciembre de 2008, por la que se aprueba el Reglamento Específico de Producción Integrada de fresa. Consejería de Agricultura, Pesca y Medio Ambiente. BOJA N ${ }^{\circ}$, de 5 de enero de 2008. Boletín Oficial de la Junta de Andalucía (BOJA), Sevilla, España.

Bringhurst, R.S., D.V. Shaw, and V. Voth. 1994. Strawberry plant called 'Camarosa'. US PP8708P. U.S.: Plant Patent nr 5,262. The Regents of the University of California, California, USA.

Buitenhuis, R., L. Shipp, and C. Scott-Dupree. 2009. Intra-guild vs. extra-guild prey: effect on predator fitness and preference of Amblyseius swirskii (Athias-Henriot) and Neoseiulus cucumeris (Oudemans) (Acari:Phytoseiidae). Bulletin of Entomological Research 100:167-173.

Buitenhuis, R., L. Shipp, C. Scott-Dupree, A. Bromit, and W. Lee. 2014. Host plant effects on the behaviour and performance of Amblyseius swirskii (Acari: Phytoseiidae). Experimental and Applied Acarology 62:171-180.

Cakmak, I., A. Janssen, M.W. Sabelis, and H. Baspinar. 2009. Biological control of an acarine pest by single and multiple natural enemies. Biological Control 50:60-65.

Calvo, F.J., K. Bolckmans, and J.E. Belda. 2011. Control of Bemisia tabaci and Frankliniella occidentalis in cucumber by Amblyseius swirskii. BioControl 56:185-192.

Chow, A., A. Chau, and K.M. Heinz. 2010. Compatibility of Amblyseius (Typhlodromips) swirskii (Athias-Henriot) (Acari: Phytoseiidae) and Orius insidiosus (Hemiptera: Anthocoridae) for biological control of Frankliniella occidentalis (Thysanoptera: Thripidae) on roses. Biological Control 53:188-196.

Cloutier, C., and S.G. Johnson. 1993. Predation by Orius tristicolor (Hemiptera: Anthocoridae) on Phytoseiulus persimilis (Acarina: Phytoseiidae): Testing for compatibility between biocontrol agents. Environmental Entomology 22:477-482.

Coll, M., S. Shakya, I. Shouster, Y. Nenner, and S. Steinberg. 2007. Decision-making tools for Frankliniella occidentalis management in strawberry: consideration of target markets. Entomologia Experimentalis et Applicata 122:59-67.

Collier, T., and R. Van Steenwyk. 2004. A critical evaluation of augmentative biological control. Biological Control 31:245-256.

de Menten, N. 2011. FresaProtect: the use of a cocktail of parasitoids against aphids in strawberries-a case study. IOBC/WPRS Bulletins 70:217-223

Elsawi, S.A., and M.M. Alazzazy. 2007. Development and reproduction of the two predatory mites Euseius scutalis and Typhlodoromips swirskii (Acari: Phytoseiidae) as affected by leaf texture of strawberry plants. Arab Universities Journal of Agriculture Sciences 15:535-542.
FAOSTAT. 2012. Organización de las Naciones Unidas para la Alimentación y la Agricultura. Sección de Estadística. Available at http://faostat3.fao.org/ (accessed 27 November 2014).

Fejt, R., and V. Jarosik. 2000. Assessment of interactions between the predatory bug Orius insidiosus and the predatory mite Phytoseiulus persimilis in biological control on greenhouse cucumber. Plant Protection Science 36:85-90.

Fitzgerald, J., N. Pepper, M. Easterbrook, T. Pope, and M. Solomon. 2007. Interactions among phytophagous mites, and introduced and naturally occurring predator mites, on strawberry in the UK. Experimental and Applied Acarology 43:33-47.

Frank, S.D. 2010. Review: Biological control of arthropods pests using banker plant systems: past progress and future directions. Biological Control 52:8-16.

Fraulo, A.B., and O.E. Liburd. 2007. Biological control of two spotted spider mite, Tetranychus urticae, with predatory mite, Neoseiulus californicus, in strawberries. Experimental and Applied Acarology 43:109-119.

Gerson, U., and P.G. Weintraub. 2007. Mites control for the pests in protected cultivation. Pest Management Science 63:658-676.

Greco, N.M., N.E. Sánchez, and G.G. Liljesthröm. 2005. Neoseiulus californicus (Acari: Phytoseiidae) as a potential control agent of Tetranychus urticae (Acari: Tetranychidae): Effect of pest/ predator ratio on pest abundance on strawberry. Experimental and Applied Acarology 37:57-66.

Hancock, J., and D. Simpson. 1995. Methods of extending the strawberry season in Europe. HortTechnology 5:286-290.

Heon, Y.H., and S.G. Park. 2006. Optimum release times for biological control of the two-spotted spider mite Tetranychus urticae Koch (Acari: tetranychidae) by Phytoseiulus persimilis Athias-Henriot (Acari: Phytoseiidae) on the strawberry in greenhouses. Entomological Research 36:238-344.

Hoy, M.A. 2011. Agricultural acarology. Introduction to integrated mite management. CRC Press, Taylor \& Francis, Boca Raton, Florida, USA.

Junta de Andalucía. 2011. Evaluación de la campaña 2010/11 de fresa y frambuesa en la provincia de Huelva. p. 14. Junta de Andalucía, Consejería de Agricultura y Pesca, Sevilla, España. Available at http://www.juntadeandalucia.es/agriculturaypesca/observatorio/ servlet/FrontController?action=DownloadS\&table $=11030 \&$ elem ent $=686068 \&$ field $=$ DOCUMENTO $($ accessed July 2014).

Junta de Andalucía. 2014. Relación de productos autorizados en Producción Integrada. Cultivo: Fresa. p. 4. Junta de Andalucía, Consejería de Agricultura, Pesca y Medio Ambiente, Sevilla España. Available at http://www.juntadeandalucia.es/ agriculturaypesca/portal/export/sites/default/comun/galerias/ galeriaDescargas/minisites/raif/sv_sustancias/insecticidas/ PFAutorizadosProdIntegrada_fresa.pdf (accessed July 2014).

Kutuk, H., A. Yigit, R. Canhilal, and M. Karacaoglu. 2011. Control of western flower thrips (Frankliniella occidentalis) with Amblyseius swirskii on greenhouse pepper in heated and unheated plastic tunnels in the Mediterranean region of Turkey. African Journal of Agricultural Research 6:5428-5433.

López-Aranda, J.M. 2008. El cultivo de la fresa en Huelva. In La fresa de Huelva. Junta de Andalucía, Consejería de Agricultura y Pesca, Sevilla, España.

MacNaeidhe, F. 1999. Out of season strawberry production under polythene. 45 p. Teagasc Soft Fruit Research Station, Dublin, Ireland.

Onzo, A., M.W. Sabelis, and R. Hanna. 2014. Single versus multiple enemies ad the impact on biological control of spider mites in cassava fields in West-Africa. Experimental and Applied Acarology 62:293-311.

Palevsky, E., A. Walzer, S. Gal, and P. Schausberger. 2008. Evaluation of dry-adapted strains of the predatory mite Neoseiulus californicus for spider mite control on cucumber, strawberry and pepper. Experimental and Applied Acarology 45:15-27.

Pottorff, L.P., and K.L. Panter. 2008. Integrated pest management and biological control in high tunnel production. HortTechnology 19:61-65. 
Quinn, G.P., and M.J. Keough. 2006. Experimental design and data analysis for biologist. Cambridge University Press, Cambridge, UK.

Rasmy, A.H., G.M. Abou-El Ella, and H.E. Hussein. 2004 Cannibalism and interspecific predation of the phytoseiid mite, Amblyseius swirskii. Journal of Pest Science 77:23-25.

Rahman, T., H. Spafford, and S. Broughton. 2011. Single versus multiple releases of predatory mites combined with spinosad for the management of western flower thrips in strawberry. Crop Protection 30:468-475.

Rhodes, E.M., and O.E. Liburd. 2006. Evaluation of predatory mites and acramite for control of two spotted spider mites in strawberries in North Central Florida. Journal of Economic Entomology 99:1291-1298.

Rhodes, E.M., O.E. Liburd, C. Kelts, S.I. Rondon, and R.R Francis 2006. Comparison of single and combination treatments of Phytoseiulus persimilis, Neoseiulus californicus, and Acramite (bifenazate) for control of two spotted spider mites in strawberries. Experimental and Applied Acarology 39:213-225.

Sáenz-de-Cabezón, I.F.G., F.G. Zalom, and J.F. López-Olguín. 2010. A review of recent patents on macroorganisms as biological control agents. Recent Patents on Biotechnology 4:48-64.

Schausberger, P., and A. Walzer. 2001. Combined versus single species release of predaceous mites: Predator-predator interactions and pest suppression. Biological Control 20:269-278.

Shakya, S., M. Coll, and P.G. Weintraub. 2010. Incorporation of intraguild predation into a pest management decision-making tool: the case of thrips and two pollen feeding predators in strawberry. Journal of Economic Entomology 103:1086-1093.

Strand, L. 2008. Integrated pest management for strawberries. $2^{\text {nd }}$ ed. University of California Agriculture and Natural Resources Publication 3351. 176 p. University of California, Oakland, California, USA

Tommasini, M.G., J.C. van Lenteren, and G. Burgio. 2004. Biological traits and predation capacity of four Orius species on two prey species. Bulletin of Insectology 57:79-93. van Baal, E., Y. van Houten, H. Hoogerbrugge, and K. Bolckmans. 2007. Side effect on thrips of the spider mite predator Neoseiulus californicus. Proceedings of Netherland Entomological Society Meeting 18:37-42.

Van Leeuwen, T., J. Vontas, A. Tsagkarakou, W. Dermauw, and L. Tirry. 2010. Acaricide resistance mechanisms in the two-spotted spider mite Tetranychus urticae and other important Acari: A review. Insect Biochemistry and Molecular Biology 40:563-572.

Voth, V., D.V. Shaw, and S. Bringhurst. 1994. Strawberry plant called 'Camarosa'. United States Patent Plant USPP8708.

Walzer, A., S. Blumel, and P. Shausberger. 2001. Population dynamics of interacting predatory mites, Phytoseiulus persimilis and Neoseiulus californicus, held on detached bean leaves. Experimental and Applied Acarology 25:731-743.

Weintraub, P.G., S. Pivonia, and S. Steinberg. 2011. How many Orius laevigatus are needed for effective western flower thrips, Frankliniella occidentalis, mangement in sweet pepper? Crop Protection 30:1443-1448.

Wimmer, D., D. Hoffmann, and P. Schausberger. 2008. Prey suitability of western flower thrips, Frankliniella occidentalis, and onion thrips, Thrips tabaci, for the predatory mite Amblyseius swirskii. Biocontrol Science and Technology 18:541-550.

Xu, X., C. Borgemeister, and H.M. Poehling. 2006. Interactions in the biological control of western flower thrips Frankliniella occidentalis (Pergande) and two-spotted spider mite Tetranychus urticae Koch by the predatory bug Orius insidiosus Say on beans. Biological Control 36:57-64.

Xu, X., and A. Enkegaard. 2010. Prey preference of the predatory mite, Amblyseius swirskii between first instar western flower thrips Frankliniella occidentalis and nymphs of the twospotted spider mite Tetranychus urticae. Journal of Insect Science 10:149. doi:10.1673/031.010.14109.

Zalom, F.G., M.P. Bolda, S.K. Dara, and S. Joseph. 2014. Insect and mites. In UC IPM Pest Management Guidelines: Strawberry. UC IPM Publication 3468. p. 17-62. University of California Agriculture and Natural Resources, Richmond, California, USA. 